\title{
Development of a CE-UV methodology for the evaluation of the addition of adsorbents in animal feed for the removal of mycotoxins: effect on the levels of B-complex vitamins
}

\author{
Carolina M. Camargo*, Ana Valéria Colnaghi Simionato.
}

\begin{abstract}
Mycotoxins are toxic substances produced by fungi metabolism and can be eventually found in animal feed, leading to potential harm in animal health. Adsorbent products are added during the production of feed in order to remove mycotoxins. However, scientific reports indicate that they can also remove some essential nutrients for health, such as vitamins, lowering the nutritional value of the animal feed. The aim of the present work is to apply Micellar Electrokinetic Capillary Chromatography (MEKC) as a tool to determinate the levels of B vitamins present in in vitro samples, simulating animal digestion of feed containing different adsorbents.
\end{abstract}

Key words: Capillary electrophoresis, Mycotoxin, Vitamins.

\section{Introduction}

Vitamins are organic substances not produced by the animal organism, thus needing to be supplied by the diet. There are two major groups of vitamins: water-soluble and fat-soluble. B vitamins are water soluble and are grouped according to their similar chemical characteristics. In this work, vitamins B1, B2, B3 and B6 were studied. Mycotoxins are secondary toxic metabolites produced by filamentous fungi. Different approaches to remove the mycotoxins from animal feed can be applied, such as the physical separation of mycotoxins from the contaminated feed, detoxification and inactivation. In the last two methods, sequestering agents are added to the feed aiming to reduce the toxicity of mycotoxins and their intestinal absorption, thus protecting the animals from future occurrences of chronic pathologies and performance losses. Such agents are indigestible adsorbent materials such as silicates and active coals. However, studies indicate that they do not absorb only the mycotoxins but also nutrients present in the animal diet. This project applies Capillary Electrophoresis (CE-UV) in the MECK separation mode to detect and quantify the levels of complex B vitamins found in in vitro samples, submitted to the treatment with different mycotoxins adsorbents. Herein we present method development for future application to in vitro samples.

\section{Results and Discussion}

To optimize vitamins separation several parameters were evaluated. Two $\mathrm{pH}$ adjustments were evaluated: a broader one - in the range of 8.5 to 9.5 (with increments of 0.5 units of $\mathrm{pH}$ ) and a narrower one - in the range of 8.0 to 9.0 (with increments of 0.2 units of $\mathrm{pH}$ ). The optimum $\mathrm{pH}$ was defined as the one in which the greatest differences in analytes apparent mobility were observed, as shown in Figure 1.

The concentration of sodium dodecyl sulfate (SDS) in the background electrolyte (BGE) concentration was also optimized. $90 \mathrm{mmol} / \mathrm{L}$ SDS concentration was selected since it resulted in the maximum resolution between consecutive peaks, as shown in Figure 2.

The experimental analysis were performed in a capillary electrophoresis system Agilent 7100 . Voltage applied was $25 \mathrm{kV}$ and the detection wavelength was $214 \mathrm{~nm}$. The effective length of fused silica capillary was $51,5 \mathrm{~cm} \times$ $50 \mu \mathrm{m}$ i.d. Capillary was daily rinsed with $\mathrm{NaOH} 1 \mathrm{M}$, $0.1 \mathrm{M}$, pure water for 15 minutes and SDS for 30 minutes.

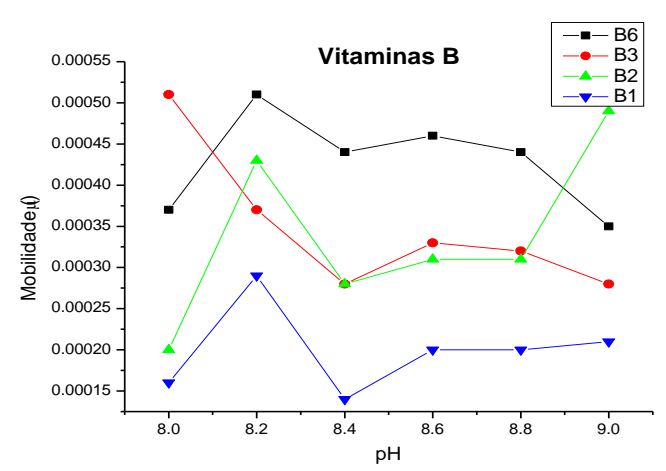

Figure 1. Difference between the apparent mobilities of vitamins $\mathrm{B} 1, \mathrm{~B} 2, \mathrm{~B} 3$ and $\mathrm{B} 6$ in $\mathrm{BGEs}$ with $\mathrm{pHs}$ ranging from 8.0 to 9.0 .

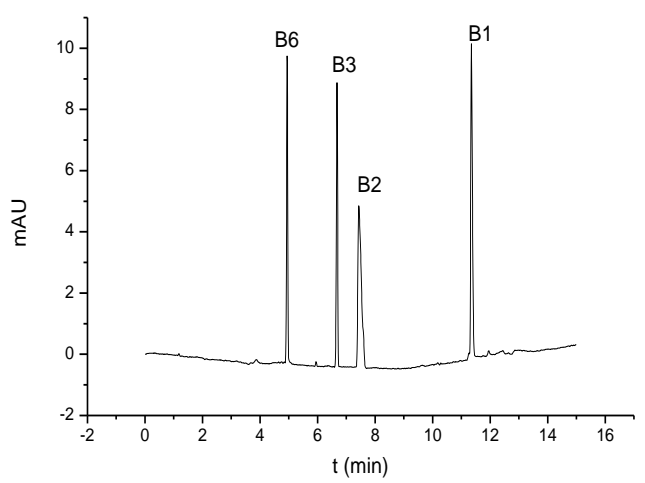

Figure 2. Electropherogram of $1 \mathrm{mmol} / \mathrm{L}$ vitamins with BGE composed of $40 \mathrm{mmol} / \mathrm{L}$ boric acid at $\mathrm{pH} \mathrm{8,6}$ and 90 $\mathrm{mmol} / \mathrm{L}$ SDS.

\section{Conclusions}

The ideal BGE for the separation of vitamins B1 B2, B3 and $\mathrm{B} 6$ is composed of $40 \mathrm{mmol} / \mathrm{L}$ borate at $\mathrm{pH} 8.6$ and $90 \mathrm{mmol} / \mathrm{L}$ SDS. The project is still in progress and validation of the method to apply it to the analyses of in vitro samples is underway.

Amaral, E. I.; Vaz, G. C. S.; Teixeira, M. A. G. Rev. Virtual Quim., 17661779. 2015.

Kadakal, Ç., Poyrazoglu, E. S., Artik, N., Nas, S. Journal of Food Quality, 27, 171-180, 2004.

Vekiru, E. et al.. Mycotoxin Research, 23 (1), 27-33, 2007 